\title{
Analysis on the Development Status and Prospects of the Intelligent Pension Model in Tianjin
}

\author{
Mingyuan Xia ${ }^{*}$, Bolin Wu, Tangrun Li \\ Statistics Department, Tianjin University of Finance and Economics, Tianjin City, China \\ Email address: \\ xiamingyuan1213@163.com (Mingyuan Xia), bonn_wu@163.com (Bolin Wu),18845000975@126.com (Tangrun Li) \\ ${ }^{*}$ Corresponding author
}

\section{To cite this article:}

Mingyuan Xia, Bolin Wu, Tangrun Li. Analysis on the Development Status and Prospects of the Intelligent Pension Model in Tianjin. Humanities and Social Sciences. Vol. 7, No. 1, 2019, pp. 34-48. doi: 10.11648/j.hss.20190701.15

Received: January 17, 2019; Accepted: April 16, 2019; Published: April 28, 2019

\begin{abstract}
The issue of old-age care has become a topic of widespread concern. With the development of technology, the intelligent mode of old-age care has emerged. Based on the online intelligent mode, Tianjin Leling Intelligent Care Co., Ltd. has added and strengthened offline services, creating a new way of old-age care: $\mathrm{O} 2 \mathrm{O}$ intelligent care mode. Delegated by the company, this study is based on the company's existing 19 community centers in Tianjin and the elderly (less than 60 years old) who live within a radius of 5 kilometers and have self-care ability are surveyed. By the investigation, this paper finds that the current situation of $\mathrm{O} 2 \mathrm{O}$ intelligent care is as follows: this mode has a certain degree of recognition, but not high; this mode is not enough for advertisement; this mode has the best satisfaction with the elderly, but the price of $\mathrm{O} 2 \mathrm{O}$ intelligent care is not satisfactory. For the current user, the situation is as follows: the age of user prefers for younger; the choice of $\mathrm{O} 2 \mathrm{O}$ intelligent care has nothing to do with the annual income of the elderly family; it is less satisfied with font size and operational difficulty; the "objective" elderly is the main customer of $\mathrm{O} 2 \mathrm{O}$ intelligent care. In conclusion, $\mathrm{O} 2 \mathrm{O}$ intelligent care is the trend of old-age care in the future and it has great potential in the market. Based on the above analyses, this paper gives detailed suggestion for the company.
\end{abstract}

Keywords: O2O Intelligent Care Mode, Entropy Weighting Ideal Point Method, K-Means, Logit Model

\section{Introduction}

Population ageing [1] is a social problem for Tianjin City even for China. As of the end of October 2017, the number of elderly people aged 60 or over in Tianjin exceeded 2.4 million, which means one out of every five people. The traditional home-based care model is not well attended by many elderly people due to the busy daily work of their children. On the other hand, nursing homes and community care for the elderly can not meet the needs of the elderly in terms of health, safety, happiness. In addition, most elderly people have solidified thought and are not willing to accept nursing home, day care center, etc. Therefore, the problem of old-age care has fallen into a contradictory situation, and the intelligent mode of old-age care (i.e., smart home care) comes into being. Smart home care is a newly popular concept of old-age care, specifically, the health of the elderly is detected through smart watches, data is transferred to nearby hospitals and children's mobile phones, and the smart watch sets a key call mechanism for calling children.

However, current smart pension products and services int the market are very narrow. In the Internet+ era, hundreds of companies specialize in the development of smart online facilities (such as the production of smart watches, online cloud data processing systems, etc.), who pay attention to the health of the elderly but ignore their entertainment, convenience and basic living needs.

Tianjin Leling Intelligent Care Co., Ltd., the first and only smart pension company in Tianjin, constructs a set of online system based on smart watches (such as old-age health information feedback detection system, health information network connected with hospital websites near the community, one-click call for help mechanism), builds a complete offline system (such as elderly university, regular health check-ups in health lodges, mental lodges, and lower-priced old-age canteens and supermarkets paid through smart watches), and provides a perfect alarm system for children (such as infrared fall alarm, smoke alarm, and gas alarm). They creat a new way 
of old-age care, i.e., $\mathrm{O} 2 \mathrm{O}$ smart pension mode.

The Leling Intelligent Care company was established in December 2009, and as of April 2018, there have been 19 community business offices. The company has gradually built a model of raising the old-age ecology and become the creator of the intelligent old-age industry chain. Delegated by the company, this paper makes analysis on the development status and prospects of the intelligent pension model in Tianjin, and furthermore put forward effective suggestions for the company to formulate a market strategy, such that the current development status and prospects of the $\mathrm{O} 2 \mathrm{O}$ intelligent pension model can be known comprehensively.

Related Work. The issue of old-age care has become a major topic to be solved in the world, and intelligent pension provides an effective way to solve this problem in the current situation of resources shortage for old-age care and medical. Research [3] shows that the family pension function has been gradually weakened with the development of the market economy in recent years. On the other hand, due to insufficient funds and lack of management, the old-age care institutions are unable to meet the individualized needs of the elderly, and the life satisfaction of the elderly is affected.

Currently, more and more scholars believe that the traditional pension model should be changed and more efforts should be put into the smart pension industry. Yong et al.[14] point out that the backwardness in science and technology and the lack of specialization are the two main factors restricting the development of China's pension industry, and developing intelligent pensions will become an important method to solve the current situation of old-age care. They put forward the insights on development process, development advantages and development prospects of the intelligent old-age care concept, such as "how to realize smart pension", "how to regulate smart old-age care", and "exploration and practice of intelligent old-age care", etc. Sheng et al.[2] shows intelligent pension has a huge potential market using unconditional logistic regression model.

In China, the State Council issued the guiding opinions on actively promoting "Internet +" actions, which clearly stated the objectives and tasks of promoting the development of smart pension industries. It shows intelligent pension has been up to national strategic level. At present, the services and technology products [4-8] put into use in China are not developed, and there is lack of pension mode combining online with offline. Therefore, $\mathrm{O} 2 \mathrm{O}$ intelligent care service is facing challenges and opportunities with greater development space. This paper carries out an analysis of the development status and prospects of the intelligent pension model in Tianjin.

\section{Scheme Design}

\subsection{Motivation}

Based on the online intelligent mode, Tianjin Leling
Intelligent Care Co., Ltd. has added and strengthened offline services, creating a new way of old-age care: $\mathrm{O} 2 \mathrm{O}$ intelligent care mode. Delegated by the Leling company, this paper explores the feasibility of this new intelligent pension model in Tianjin and propose effective recommendations for the company to develop a market strategy. Specifically, the purpose of research is to understand the development status and satisfaction status of Tianjin $\mathrm{O} 2 \mathrm{O}$ intelligent pension model, determine the main customers, and explore the prospects of Tianjin $\mathrm{O} 2 \mathrm{O}$ intelligent pension model. The structure of research is de in Figure 1.

\subsection{Description of Scheme}

This paper adopts a combination of qualitative and quantitative methods, focusing on quantitative analysis. In the market satisfaction evaluation of $\mathrm{O} 2 \mathrm{O}$ intelligent pension model, this evaluation model is based on entropy weight and ideal point method. In the exploration of influence factors on the prospects of the $\mathrm{O} 2 \mathrm{O}$ intelligent pension model, the Logit model is used.

For the market satisfaction status of $\mathrm{O} 2 \mathrm{O}$ intelligent pension model, this research focuses on the comparison among different pension methods in term of comprehensive satisfaction and many indicators such as pension price, pension quality, pension environment, convenience level, and comfort level. In general, the customer satisfaction index model (CSI) and the structural equation model are used to construct relevant satisfaction models. CSI consists of four macro levels (i.e., national overall satisfaction index, department satisfaction index, industry satisfaction index and business satisfaction index) and is a great customer satisfaction model. However, CSI seems very redundant and macroscopic for this research, and thus it is not suitable. The structural equation model focuses on the degree of influence of the subordinate satisfaction index on its upper level satisfaction index, which is also inconsistent with this research purpose. Therefore, these two models are not chosen in this paper.

In the model based on entropy weight and ideal point method, the satisfaction of the elderly in a single mode comprehensively can be evaluated. Moreover, the evaluation resulsts of different modes can be put in order, so that horizontal comparsion of each pension mode in terms of user satisfaction can be obtained, which is in line with this research purposes. In addition, in this model, the weight is determined from the information contained in the original data, avoiding the influence of the subjective factors of the elderly on the weight distribution, and thus the evaluation has relative objectivity. Furthermore, the operation in this model is simple and it can be conveniently used in the case of relatively large evaluation indexes. Therefore, the model based on entropy weight and ideal point method is chosen in this paper. 


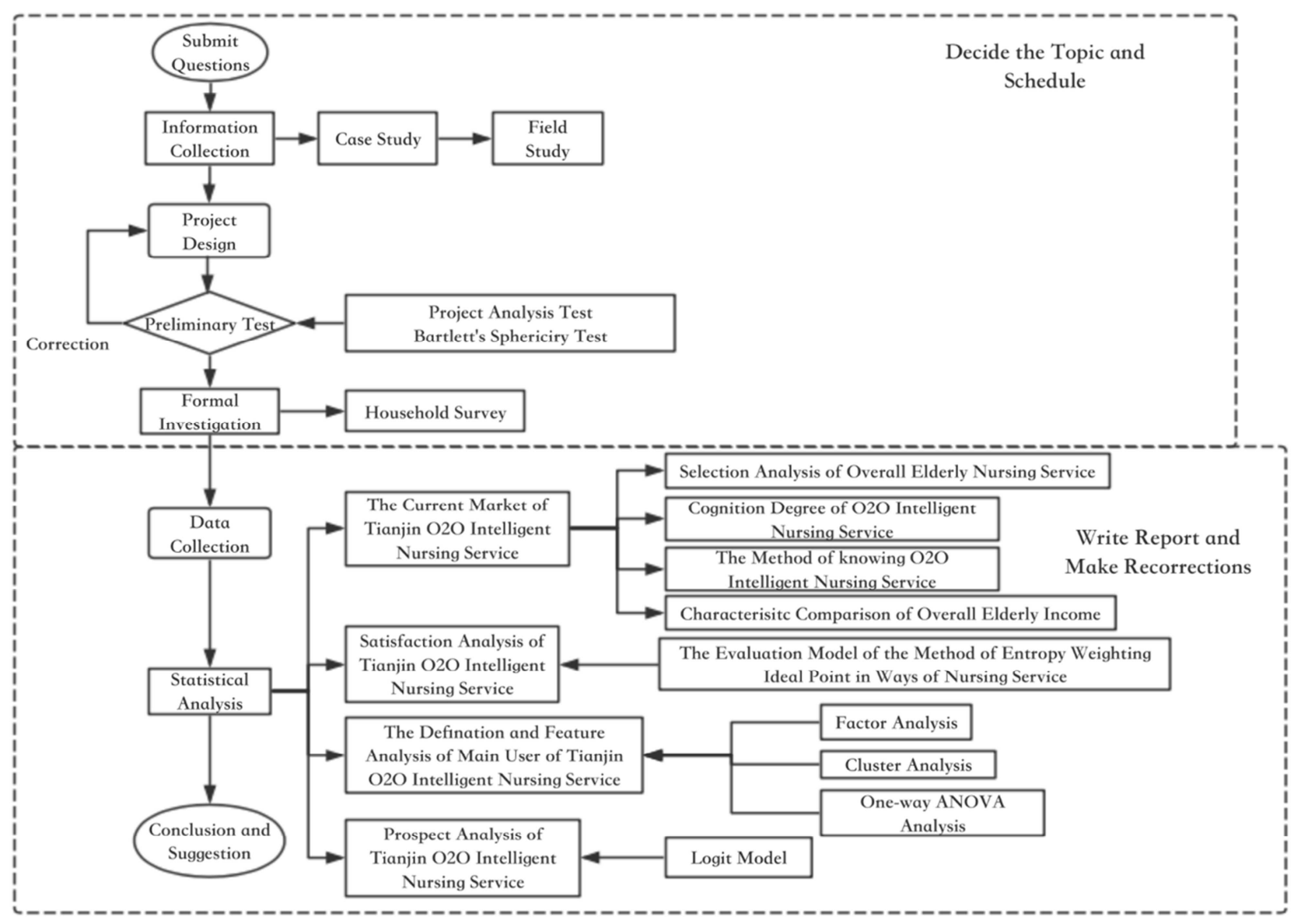

Figure 1. The Structure of Research.

This paper chooses Logit model to explore which influence factor having greater impact on $\mathrm{O} 2 \mathrm{O}$ intelligent pension. In fact, Logit model is the expansion of ordinary multiple linear regression models. Using the linear decisional model to calculate the $\mathrm{Z}$ value is only an abstract concept, which can only be used to decide but not explain by intuition, however, the Logit model can solve this problem. Specifically, the Logit model can overcome the shortcomings of the traditional Mantel-Haenszel analysis method and linear regression analysis. It can analyze multiple factors including discrete random variables and continuous random variables at the same time, and it also can effectively analyze the mixed effects and interactions of external variables, which is closer to the objective situation, and thus a more reasonable explanation of the result can be obtained. In addition, Logit model is the most suitable for fitting anlysis by comparing the goodness of fit of different models.

\subsection{Innovation}

Previous market research on the intelligent pension model is only aimed at the online mode. This paper chooses $\mathrm{O} 2 \mathrm{O}$ smart pension model, an emerging and widely-respected pension model as a research object, by cooperating with the only $\mathrm{O} 2 \mathrm{O}$ smart pension company in Tianjin, such that the development status and the prospects of $\mathrm{O} 2 \mathrm{O}$ smart pension can be understood, and furthermore recommendations for the company on how to develop potential users and how to retain existing users can be made.

\section{Design of Survey Scheme}

\subsection{Background}

The company has 19 community outlets and the sites are selected according to the following rules: (1) the majority of the residents in the community are elderly; and (2) it is located near the old community. This paper conducts this survey based on the existing 19 community outlets.

\subsection{Method}

This paper conducts household surveys. The interviewer first explains the survey institution and the purpose of the survey to the interviewee, seeks the consent of the interviewee, and then introduces the survey questionnaire and provides assistance for the interviewee filling out the questionnaire. Finally, the interviewer carefully checks whether the questionnaire being complete and accurate, and conducts an audit of the completeness, accuracy and logic of the questionnaire.

Considering that some elderly people have difficulty answering the questions, this paper asks people who are familiar with the situation of the elderly, such as children and nannies, to answer the questions for them. The problem in more detail in the early stage will be explained such that the 
communication among the interviewer, the respondent and the interviewed old person is as accurate as possible, avoiding the deviation. Actually, all the elderly surveyed can answer the question by themselves in this survey.

\subsection{Design of Scheme}

\subsubsection{Object}

The current intelligent pension service is mainly for the elderly who can take care of themselves, and thus the object of this survey is these elderly who are 60 years of age or older. This investigation uses the "ADL scale" system commonly used in rehabilitation medicine to judge whether the elderly people surveyed can take care of themselves. The content of the measurement is divided into six items (i.e., go to the toilet, eat, dress, wash, walk and bath), the degree is from light to heavy (i.e., fully self-care, partially difficult, need help, can't self-care) and assigned from 1 to 4 , respectively, which means that the higher the score, the lower the self-care ability. According to the reference [9-13], the evaluation rules at the time of the questionnaire survey are obtained: only the elderly with a total score of 9 or less can take care of themselves.

According to the information from the company, the elderly who lives the farthest is $5.21 \mathrm{~km}$ away from the community business location. According to "five kilometers of marketing standards" principle, survey area is an area with a radius of 5 $\mathrm{km}$ or less centered on the community business location.

Finally, the object of this survey is determined, that is, the elderly who are 60 years of age or older with the self-care ability, and live within a radius of $5 \mathrm{~km}$ or less centered on 19 community outlets in Tianjin.

\subsubsection{Sample Size}

\section{(1) Pre-survey}

In the pre-survey, the research topics and the contents of the questionnaires are discussed repeatedly, opinions of the respondents are solicited, some ambiguous, overly abstract and unnecessary problems are deleted, and the order of the questions in the questionnaire is slightly adjusted, which lays a solid foundation for formal investigation. Particularly, 80 questionnaires were sent out, 71 were valid, and the effective rate of the questionnaire was $88.75 \%$.

(2) Sample Size

The sample size depends on the degree of variation of the subject, accuracy requirements, confidence requirements, overall size, and sampling methods. The formula is used to calculate the sample size, and the maximum variance can be calculated by SPSS. It sets relative error limit does not exceed $7.5 \%$ (i.e., absolute error limit $\mathrm{d}=0.15$ ), and the confidence level is $99 \%$. The calculated initial sample size is about 795 .

According to the pre-survey questionnaire, the effective response rate is $71 / 80$ (i.e., $88.75 \%$ ), and the sample size is re-adjusted to 896. Taking into account the actual situation, the sample size is increased by 100 , and finally is 996 .

\subsubsection{Design of Sampling}

This survey is with a radius of $5 \mathrm{~km}$ or less centered on 19 community business location. The sample size of each area is calculated according to the proportion of the number of elderly people in the $\mathrm{O} 2 \mathrm{O}$ smart pension mode recorded by each community business site. Specifically, the sample size of each area is $52,47,66,39,49,57,50,43,57,63,52,53,61,49$, $45,60,35,58$, and 60 , respectively.

Selection of Community. The area with a radius of 5 kilometers centered on the community business site is divided into five areas of 0-1 km, 1-2 km, 2-3 km, 3-4 km, and 4-5 km. This paper lists the community names in each region separately (For cross-regions community, it belongs to the region with a large area), sort by computer-generated random numbers 1-50, and extract them starting from a small number of communities in each area. The five areas are sampled as much as possible. If it cannot be equally divided, the remaining sample is randomly assigned to each area.

Selection of Household. According to the principle of randomness, this paper adopts an equidistant sampling method.

i Each community is arranged from small to large, and the odd number is extracted from small to large.

ii The right households of the even-numbered floors of the sampled building are sampled. If there is no one on the right side, the upstairs households are replaced; and skipped if no one upstairs.

\subsection{Evaluation on Survey Questionnaire}

\subsubsection{Content Analysis}

By sorting the total scores from high to low, the score of the upper $27 \%$ is 81 , and the score of the lower $27 \%$ is 62 . The total score is tested by the sample difference t-test, and the result shows $t$ values in the results are all significant ( $\mathrm{P}$ value is less than 0.05), indicating that all of 18 questions have a degree of discrimination and can identify the reaction level from different subjects. Therefore, the questionnaire passes the project analysis test.

\subsubsection{Rliability Test}

Reliability is the degree of consistency of results obtained by repeating measurements on the same object in the same way. Cronbachais the coefficient of reliability commonly used. By the reliability analysis of a questionnaire, whether the questionnaire has stability and reliability can be judged.

This paper uses SPSS software to make a reliability analysis of the questionnaire, and the Cronbach's alpha coefficient is shown in Table 1. From Table 1, the Cronbach's $\alpha$ coefficient of the questionnaire is $0.805>0.8$, which shows the reliability is good and this questionnaire has stability and reliability. In Table 1, the reliability coefficient above 0.9 means the reliability is very good; the reliability coefficient between 0.8 and 0.9 means the reliability is acceptable; the reliability coefficient between 0.7 and 0.8 means some projects need to be revised; and the reliability coefficient below 0.7 means some projects need to abdoned.

Table 1. Cronbach $\alpha$ Coefficient.

\begin{tabular}{ll}
\hline Cronbach $\alpha$ & Standardized Cronbach $\alpha$ \\
\hline 0.805 & 0.804 \\
\hline
\end{tabular}




\section{Current Market Situation of $\mathrm{O2O}$ Intelligent Pension in Tianjin}

In this survey, questionnaires are used. The questionnaire recovery rate is $100 \%$, and the effective questionnaire rate is $94.98 \%$. The overall situation of the valid questionnaires is that 348 elderly people surveyed are $\mathrm{O} 2 \mathrm{O}$ intelligent old-age users, and the remaining 598 elderly people surveyed choose other types of old-age care.

\subsection{Analysis of Old-age Care Choice}

On average, most surveyed elderly in Tianjin choose traditional home-based pensions, accounting for $50.9 \%$ of the total, followed by $\mathrm{O} 2 \mathrm{O}$ smart pension model and online smart pension, accounting for $36.8 \%$ and $8.3 \%$ respectively, while rates of chosing nursing homes and other pension options are lower, at $1.7 \%$ and $2.3 \%$ respectively. The $\mathrm{O} 2 \mathrm{O}$ smart pension model has a certain market.

\subsection{Analysis of O2O Intelligent Pension Cognition}

Among the 946 elderly people surveyed, only 416 elderly people (about $43.92 \%$ ) heard about $\mathrm{O} 2 \mathrm{O}$ smart pension model. This result shows that the propaganda of the $\mathrm{O} 2 \mathrm{O}$ smart pension model has a certain effect, but it has not yet become a household name.

\subsection{Ways of the Elderly Knowing O2O Intelligent Pension}

From Figure 2, it can be known that the majority of users (38.84\%) learn about $\mathrm{O} 2 \mathrm{O}$ smart retirement by their children, followed by broadcast (22.08\%), television (13.75\%), newspaper (12.67\%), "when passing by" (8.64\%), and only $7.08 \%$ of the elderly learn about it through "acquaintance introduction". This shows that the majority of the elderly are introduced by their children or by broadcast to understand $\mathrm{O} 2 \mathrm{O}$ smart retirement.

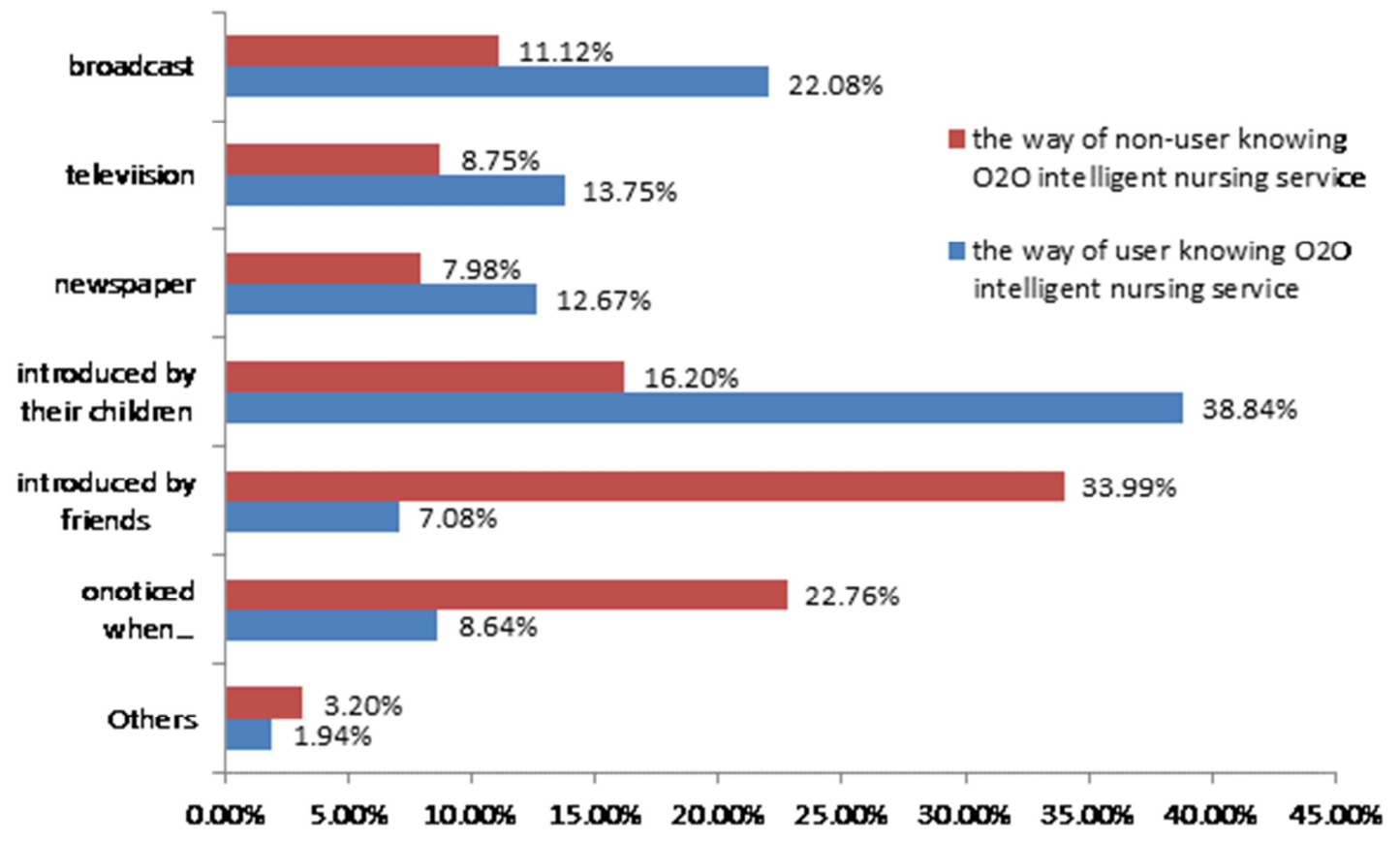

Figure 2. The way of the elderly knowing O2O intelligent nursing.

For non-user elderly, the majority of them (33.99\%) learn about $\mathrm{O} 2 \mathrm{O}$ smart retirement by "acquaintance introduction", followed by "when passing by" $(22.76 \%)$, their childern introduction $(16.20 \%)$, television $(13.75 \%)$, broadcast $(11.12 \%)$, and only $7.98 \%$ of the elderly learn about it through newspaper. This shows that the majority of the non-user elderly are introduced by acquaintance or by "passing by" to understand $\mathrm{O} 2 \mathrm{O}$ smart retirement.

In summary, whether the user elderly or non-users, most of them are introduced by their children or acquaintance. It shows that the advertisements made by enterprises are not enough and the products are not well used for marketing by TV and newspaper channels. In view of the fact that the elderly mainly access information by the radio and the cost of radio advertising is relatively small, enterprises should strengthen the advertising of radio.

\subsection{Annual Familiy Income of the Elderly Chosing Different Pension}

From Table 2, it can be known the most elderly with a family income of 150000-240000 yuan choose O2O smart pension mode, accounting for $18.10 \%$. With the annual income of the family increasing, the proportion of the elderly who choose the $\mathrm{O} 2 \mathrm{O}$ smart pension model remains unchanged. Therefore, it can be believed that whether to choose the $\mathrm{O} 2 \mathrm{O}$ smart pension model has nothing to do with the annual income of the elderly family. 
Table 2. Annual Familiy Income of the Elderly Chosing Different Pension.

\begin{tabular}{|c|c|c|c|c|c|c|c|}
\hline & & below 30000 & $30000-60000$ & $60000-150000$ & $150000-240000$ & $240000-450000$ & above 450000 \\
\hline \multirow{5}{*}{$\begin{array}{l}\text { Ratio of } \\
\text { each mode }\end{array}$} & O2O Smart & $8.02 \%$ & $24.53 \%$ & $29.89 \%$ & $18.10 \%$ & $11.78 \%$ & $7.68 \%$ \\
\hline & On-line Smart & $7.37 \%$ & $26.24 \%$ & $30.07 \%$ & $14.03 \%$ & $10.63 \%$ & $11.66 \%$ \\
\hline & Home-based & $27.45 \%$ & $24.45 \%$ & $23.67 \%$ & $6.34 \%$ & $12.04 \%$ & $6.05 \%$ \\
\hline & Nursing & $13.63 \%$ & $12.42 \%$ & $39.62 \%$ & $15.43 \%$ & $10.02 \%$ & $8.88 \%$ \\
\hline & Others & $14 \%$ & $14.67 \%$ & $38.03 \%$ & $17.62 \%$ & $7.36 \%$ & $8.32 \%$ \\
\hline
\end{tabular}

\section{Analysis of Market Satisfaction}

The $\mathrm{O} 2 \mathrm{O}$ smart retirement mode pioneered by Tianjin Leling Smart Care Co., Ltd. has been in Tianjin for nearly 10 years and has a certain customer number. In order to make the company develop better in the future, it is a top priority to improve the current service shortage and improve user satisfaction.

This part first studies the market satisfaction of $\mathrm{O} 2 \mathrm{O}$ intelligent pension model using the pension-based satisfaction evaluation model based on entropy weight and ideal point method. Then this part studies the satisfaction degree for evaluation indicators in different pension modes. Finally, using descriptive statistical analysis, the user's satisfaction with the $\mathrm{O} 2 \mathrm{O}$ intelligent pension model services is further explored.

\subsection{Market Satisfaction of O2O Smart Pension}

This paper establishes a model based on entropy weight and ideal point method to analyze the market satisfaction of Tianjin $\mathrm{O} 2 \mathrm{O}$ intelligent pension.

\subsubsection{Theory Basis}

(1) entropy and entropy weight

Entropy is an extensive property of a thermodynamic system and developed in the early 1850 s by Rudolf Clausius. Entropy is an expression of the disorder, or randomness of a system, and it is the measure of uncertainty in information theory. In 1948, Shannon introduced the definition of entropy and entropy weight. Specifically, For $\mathrm{n}$ indicators and $\mathrm{m}$ schemes, entropy $H_{j}$ and entropy weight $w_{j}$ are as follows:

$$
\begin{gathered}
V=\left(\begin{array}{llll}
v_{1}, & v_{2}, & \cdots & v_{m}
\end{array}\right) \\
V=\left(\begin{array}{llll}
v_{1}, & v_{2}, & \cdots & v_{m}
\end{array}\right)
\end{gathered}
$$

Entropy has the following properties:

(i) Symmetry. All arguments are interchangeable and do not affect the value of the amount of information.

(ii) Non-negative. $V=\left(\begin{array}{llll}v_{1}, & v_{2}, & \cdots & v_{m}\end{array}\right)$

(iii) Certainty. As long as there is a $p$ value of " 1 ", the amount of information must be zero. At this point, the random variable is a certain amount.

(iv) Additive. The amount of information in the system is equal to the sum of the amounts of state information.

(v) Extreme value. When $V=\left(\begin{array}{llll}v_{1}, & v_{2}, & \cdots & v_{m}\end{array}\right)$, amount of information is maximum and $V=\left(\begin{array}{llll}v_{1}, & v_{2}, & \cdots & v_{m}\end{array}\right)$.
(2) Positive ideal point and negative ideal point

The ideal point is a sorting method close to simple weighting, which uses the positive ideal solution and the negative ideal solution of the multi-objective decision problem to sort. The so-called positive ideal solution is the best solution and its individual attribute values reach the best value among the evaluation objects, while the negative ideal solution is the worst solution and its attribute values reach the worst value of the evaluation objects. These two extreme values can be called as positive and negative ideal points. The positive ideal point $=\{$ consisting of the optimal value of each evaluation index $\}$, the negative ideal point $=$ consisting of the worst value of each evaluation index $\}$, and the decision mode $=\{$ the scheme that is the nearest from the positive ideal point and the farthest from the negative ideal point is the most satisfactory solution $\}$.

\subsubsection{Model}

(1) Establish the original evaluation matrix of the satisfaction of the elderly in Tianjin.

Assume pension mode collection $V=\left(\begin{array}{llll}v_{1}, & v_{2}, & \cdots & v_{m}\end{array}\right)$ and evaluation index collection $Q=\left(\begin{array}{llll}q_{1}, & q_{2}, & \cdots & q_{n}\end{array}\right)$, which means there are $m$ kinds of old-care ways to accept $n$ evaluation indicators for evaluation. First, according to the evaluation index system, the elderly score each evaluation index based on experience and personal feelings, and the original evaluation matrix is obtained.

$$
X^{\prime}=\left[\begin{array}{cccc}
x_{11}^{\prime} & x_{12}^{\prime} & \cdots & x_{1 n}^{\prime} \\
x_{21}^{\prime} & x_{22}^{\prime} & \cdots & x_{2 n}^{\prime} \\
\vdots & \vdots & \vdots & \vdots \\
x_{m 1}^{\prime} & x_{m 2}^{\prime} & \cdots & x_{m n}^{\prime}
\end{array}\right]
$$

where $\mathrm{m}$ means the kinds of old-care ways, $\mathrm{n}$ means the numbers of evaluation index, and $x_{i j}$ is the evaluation score of the $\mathrm{i}$-th way and the $\mathrm{j}$-th evaluation index.

(2) Standardize the original evaluation matrix.

Among the evaluation indicators, some efficiency indicators are the bigger the better, while some cost indicators are the smaller the better. Different values of the indicators have different dimensions. In order to eliminate the influence of the attributes and dimensions of the indicators on the evaluation results, the original evaluation matrix needs to be standardized and normalized. First, the original matrix is normalized by the power factor method to eliminate the influence of indicators.

For efficiency indicators: 


$$
\bar{x}_{i j}=\frac{x_{i j}^{\prime}-\min _{i}\left(x_{i j}^{\prime}\right)}{\max _{i}\left(x_{i j}^{\prime}\right)-\min _{i}\left(x_{i j}^{\prime}\right)}
$$

For cost indicators:

$$
\bar{x}_{i j}=\frac{\max _{i}\left(x_{i j}^{\prime}\right)-x_{i j}^{\prime}}{\max _{i}\left(x_{i j}^{\prime}\right)-\min _{i}\left(x_{i j}^{\prime}\right)}
$$

Then, to eliminate the impact of different dimensions, $\bar{x}_{i j}$ is normalized as

$$
x_{i j}=\frac{\bar{x}_{i j}}{\sum_{i=1}^{m} \bar{x}_{i j}}
$$

and the standardized matrix $X=\left(x_{i j}\right)_{m \times n}$ is obtained.

(3) Determine entropy and entropy weight

According to the definition, the entropy of $j$-th evaluation index is

$$
H_{j}=-k \sum_{i=1}^{m} x_{i j} \ln x_{i j}(j=1,2, \ldots, n)
$$

where $\mathrm{k}>0$ is adjustment factor and generally $K=\frac{1}{\ln m}$. It is also assumed when $=0$. The larger the value $H_{j}$, the greater the amount of information contained in the $\mathrm{j}$-th indicator. The entropy weight $w_{j}$ is determined as formula (2) and added to standardized matrix. Thus,

$$
\begin{aligned}
& A=\left[\begin{array}{cccc}
a_{11} & a_{12} & \cdots & a_{1 n} \\
a_{21} & a_{22} & \cdots & a_{2 n} \\
\vdots & \vdots & \vdots & \vdots \\
a_{m 1} & a_{m 2} & \cdots & a_{m n}
\end{array}\right] \\
& =\left[\begin{array}{cccc}
w_{1} x_{11} & w_{2} x_{12} & \cdots & w_{n} x_{1 n} \\
w_{1} x_{21} & w_{2} x_{22} & \cdots & w_{n} x_{2 n} \\
\vdots & \vdots & \vdots & \vdots \\
w_{1} x_{m 1} & w_{2} x_{m 2} & \cdots & w_{n} x_{m n}
\end{array}\right]
\end{aligned}
$$

(4) Determine positive and negative ideal points

Accoding to the definition, the positive ideal point is $p^{+}=\left(p_{1}^{+}, p_{2}^{+}, \cdots, p_{n}^{+}\right)$, where if the $\mathrm{j}$-th index is efficency index, $p_{j}^{+}=\max \left\{a_{i j} \mid i=1,2, \ldots, m\right\}$, and if the $\mathrm{j}$-th index is cost index, $\quad p_{j}^{+}=\min \left\{a_{i j} \mid i=1,2, \cdots, m\right\}$. Correspondingly, the negative ideal point is $p^{-}=\left(p_{1}^{-}, p_{2}^{-}, \cdots, p_{n}^{-}\right)$where if the $\mathrm{j}$-th index is efficency index, $p_{j}^{-}=\min \left\{a_{i j} \mid i=1,2, \cdots, m\right\}$, and if the $\mathrm{j}$-th index is cost index, $p_{j}^{-}=\max \left\{a_{i j} \mid i=1,2, \ldots, m\right\}$.

(5) Compute the distance from each evaluated pension method to the positive and negative ideal points.

$$
\begin{gathered}
d_{i}^{+}=\sqrt{\sum_{i=1}^{n}\left(a_{i j}-p_{j}^{+}\right)^{2}}, i=1,2, \ldots, m \\
d_{i}^{-}=\sqrt{\sum_{i=1}^{n}\left(a_{i j}-p_{j}^{-}\right)^{2}}, i=1,2, \ldots, m
\end{gathered}
$$

(6) Compute the superiority degree

According to the evaluation idea of the ideal point method, the optimal evaluation scheme is the closest to the positive ideal point (the smallest value) and the farthest from the negative ideal point (the largest value). However, in fact, there is no evaluation scheme satisfing both conditions at the same time, so the superiority degree can be defined as

$$
u_{i}=\frac{d_{i}^{-}}{d_{i}^{-}+d_{i}^{+}}, \quad \mathrm{i}=1,2, \cdots, m
$$

The superiority degree is only an evaluation coefficient reflecting the old-age care method in terms of the satisfaction of the elderly. In order to obtain the comprehensive evaluation score, the superiority degree needs to be multiplied by 100 (assuming that the best value of the efficiency index is 100 and the best of the cost index is 0 ), so that the comprehensive score is $T_{i}=u_{i} \times 100$.

This model can comprehensively evaluate the satisfaction of the elderly not only in a single mode, but also in multiple old-care ways. Moreover, the superiority degree can be sorted so that each pension method can achieve a horizontal comparison in terms of user satisfaction.

\subsubsection{Results}

In this survey, there are five ways to old-care (i.e., O2O smart pension, online pension, traditional home-based pension, nursing home, and others) and five evaluation indicators (i.e., pension price, pension quality, pension environment, convenience level and comfort level). The original evaluation matrix is shown in Table 3.

Table 3. The original evaluation matrix.

\begin{tabular}{llllll}
\hline & price & quality & environments & Convenience level & Comfort level \\
\hline O2O smart & 68 & 73 & 75 & 74 & 76 \\
on-line & 69 & 70 & 66 & 71 & 71 \\
home-based & 71 & 72 & 63 & 68 & 65 \\
nursing & 68 & 62 & 62 & 66 & 65 \\
others & 58 & & 66 & 66 \\
\hline
\end{tabular}

The standardized evaluation matrix is 


$\mathrm{X}=\left[\begin{array}{ccccc}0.769231 & 1.000000 & 1.0000000 & 1.0000000 & 1.000000 \\ 0.846154 & 0.727273 & 0.357143 & 0.750000 & 0.545455 \\ 1.000000 & 0.909091 & 0.285714 & 0.875000 & 0.545455 \\ 0.769231 & 0.545455 & 0.000000 & 0.250000 & 0.000000 \\ 0.000000 & 0.000000 & 0.071429 & 0.000000 & 0.090909\end{array}\right]$

and the weight is $w=(0.088910,0.096233,0.208394,0.123037,0.165379)$.

The matrix is normalized as $A=\left[\begin{array}{lllll}0.068392 & 0.096233 & 0.208394 & 0.123037 & 0.165379 \\ 0.075231 & 0.069987 & 0.074426 & 0.092278 & 0.090207 \\ 0.088910 & 0.097484 & 0.059541 & 0.107657 & 0.090207 \\ 0.068392 & 0.052491 & 0.000000 & 0.030759 & 0.000000 \\ 0.000000 & 0.000000 & 0.014885 & 0.000000 & 0.015034\end{array}\right]$

The positive ideal point

$p^{+}=(0.088910,0.096233,0.208394,0.123037,0.165379)$

and the negative ideal point $p^{-}=(0,0,0,0,0)$.

The distance to the positive ideal point is $d^{+}=(0.020518,0.220286,0.210670,0.354166,0.366144)$ and the distance to the negative ideal point is $d^{-}=(0.388555,0.197736,0.220462,0.095873,0.036100)$.

The superiority degree of the elderly satisfaction is $u_{i}=(0.949844,0.473028,0.511356,0.213032,0.089747)$.

\subsubsection{Summary}

$\mathrm{O} 2 \mathrm{O}$ smart pension mode is closest to the ideal point. Since $u_{1}>u_{3}>u_{2}>u_{4}>u_{5}$, the best way in the elderly satisfaction is $\mathrm{O} 2 \mathrm{O}$ smart pension model. From the original evaluation matrix, it also can be known that $\mathrm{O} 2 \mathrm{O}$ smart pension model is the best in terms of evaluation indicators of pension quality, environment, convenience level and comfort level. The superiority degree of the comprehensive evaluation results is consistent with the actual, which furthermore shows the validity of the model.

Nevertherless, the user's satisfaction with the price of $\mathrm{O} 2 \mathrm{O}$ smart pension doses not reach the ideal point. For the price of $\mathrm{O} 2 \mathrm{O}$ intelligent pension model, the distance from the ideal point is the third. It shows that the company need to adapt the price strategy (e.g., price reduction) or marketing strategy (e.g., targeting consumers, taking price differences) such that the satisfaction of the price is closer to the ideal point.

\subsubsection{Model Test}

In order to more intuitively see the difference in the satisfaction degree of the old-age users in Tianjin to the various ways of old-age care, based on the combination of models, the system clustering method can be used to classfy.

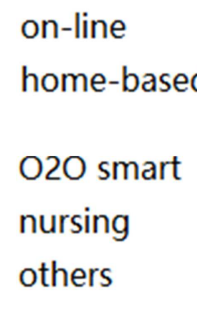

From Figure 3, it can be known all the old-age pensions in Tianjin are divided into three categories according to the satisfaction of the elderly. Specifically, the $\mathrm{O} 2 \mathrm{O}$ smart pension model is the first category, the online intelligent pension and the traditional home pension are the second category, the nursing home and others are the third category. The results of the cluster analysis are consistent with that of the satisfaction model based on the entropy weight and the ideal point method. Both of them show that the $\mathrm{O} 2 \mathrm{O}$ intelligent pension model has outstanding performance in user satisfaction, which further validates the validity of the model.

\subsection{Satisfaction of O2O Intelligent Pension}

This paper further explores the user's satisfaction with the O2O smart pension model. As can be seen from Figure 4, the elderly are most satisfied with the home security system, followed by the elderly canteen and supermarket, and health checkup again. The most dissatisfied is the size of the font on the display of the smart watch, and relatively dissatisfied is the difficulty of the operation of the watch. The smaller font makes many elderly invisible, and the operation steps (such as calling children) are so complicated for the elderly that they will forget how to operate from time to time. 


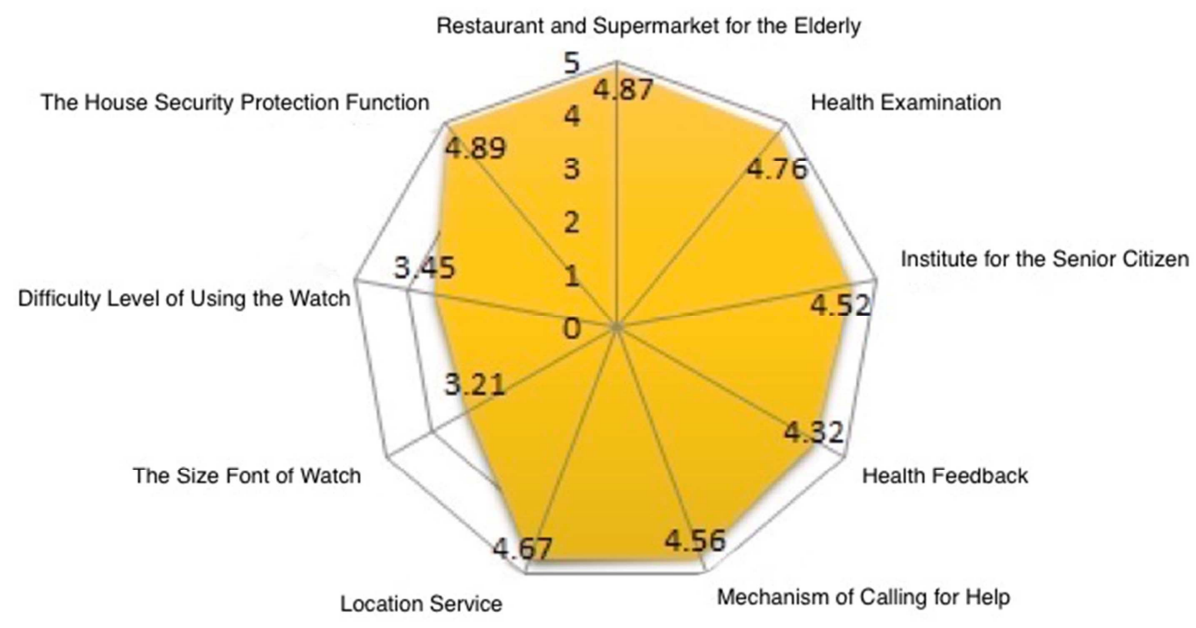

Figure 4. Satisfaction of O2O intelligent pension model.

In response to the above situation, the following suggestions are proposed: (1) increase the font size on the display of the watch, and (2) simplify the operation steps, set the third side button to directly call the child.

\section{Main Customers and Characteristics}

For the marketing promotion of companies, it is crucial to identify the main customers. By determining the characteristics of the main customers, the company can carry out more targeted publicity, improve the accuracy of publicity, and reduce the cost of manpower and material resources. Moreover, it also achieves the goal of increasing the number of users. This section obtains the main customers of Tianjin $\mathrm{O} 2 \mathrm{O}$ intelligent pension model by analyzing the factors affecting the elderly's choice of old-age care.

When choosing a pension method, each old-age people will have his own factors. Some may pay more attention to their understanding of pension ways and the quality of old-age services, or the professional knowledge obtained before they retired. However, it is not only about itself, but sometimes the influence of the outside world is also important, such as the attitude of the children, and the evaluation of other old-age people, etc.
First, this part has a general description of the influencing factors. Then, this part analyzes the factors of $\mathrm{O} 2 \mathrm{O}$ intelligent old-age users, and obtain different factors for cluster analysis to find the main customers. Finally, this part studies the characteristics of the main customers and get further conclusions.

\subsection{Influencing Factors of Choosing Pension}

By inquiring for the elderly and online access to reference, this paper developes the following seven influencing factors and divide them into five levels: very unimportant, unimportant, general, important, and very important. In the questionnaire, this paper assigns 1 to "very unimportant", 2 to "not important", 3 to "general", 4 to "important", and 5 to "very important". The specific scores of the elderly $\mathrm{O} 2 \mathrm{O}$ intelligent old-age users in Tianjin are shown in Figure 5.

From Figure 5, it can be known when the elderly are choosing the old-age care mode, the service quality of the old-age care mode has the greatest influence, followed by the pension price and the child's attitude again. The evaluation of other elderly people has the least influence, and the professional knowledge before retirement has the relatively small influence on the elderly.

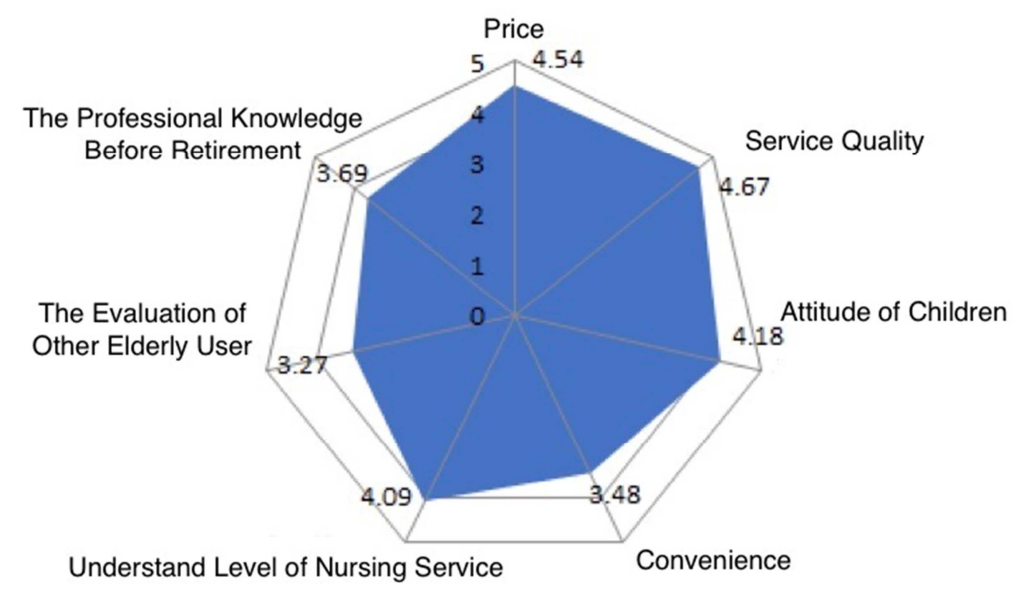

Figure 5. Factors of choosing pension. 


\subsection{Common Factors-Based on Factor Analysis}

For the above seven influencing factors, the analysis is relatively cumbersome. This paper further analyzes the factors and extract the common factors to solve the main problems.

Since the factor analysis requires a strong correlation between the original variables, this paper calculates the image matrix and make Bartlett sphericity test and KMO test, to determine whether the problem is suitable for factor analysis. The analysis results are shown in Table 4.

Table 4. KMO test and Bartlett test.

\begin{tabular}{lll}
\hline Kaiser-Meyer-Olkin test & & 0.792 \\
& Approx. Chi-Square & 623.217 \\
Bartlett sphericity test & Df & 36 \\
& Sig & 0.000 \\
\hline
\end{tabular}

The statistics of Bartlett's spherical test are obtained from the determinant of the correlation coefficient matrix. If the value is large and its corresponding $\mathrm{P}$ value is less than the significance level of the user center, then the null hypothesis should be rejected. It is considered that the correlation coefficient cannot be a unit matrix, that is, there is a correlation between the original variables, which is suitable for factor analysis. On the contrary, if the condition is not satisfied, it is insuitable for factor analysis. From the Sig. value of the Bartlett sphericity test, it can be known that the value is less than the significance level given $(0.05)$ and the null hypothesis should be rejected. It is considered that there is a significant difference between the correlation coefficient matrix and the unit matrix.

The $\mathrm{KMO}$ (Kaiser-Meyer-Olkin)test statistic is an indicator used to compare the simple correlation coefficient and the partial correlation coefficient between variables. Commonly used KMO metrics: 0.9 or more means very suitable; 0.8 means suitable; 0.7 means general; 0.6 means less suitable; 0.5 or less means extremely unsuitable. The value of the KMO test is 0.792 , which is considered to be suitable for factor analysis.

According to the principle of total variance decomposition, the factors are extracted by the rule of reflecting the information amount. Since the first four common factors can reflect $85.381 \%$ of the original information, the information loss of the original variables is less, and thus it is desirable to extract 4 common factors.

There are many methods for factor loading matrices and this paper uses principal component analysis method. By the maximum orthogonal rotation of the variance, the meaning of each common factor is easily explained and named according to the rotated factor load matrix. Then 4 common factors(i.e., price factor, technical factor, theoretical factor, and information factor) can be got and shown in Table 5.

Table 5. Name common factors.

\begin{tabular}{lll}
\hline Common factors & original index & factor \\
\hline F1 & the price of pension & price factor \\
F2 & quality and convenience & technical factor \\
F3 & previous professional knowledge、 understand level & theoretical factor \\
F4 & attitude of children vevaluation of other elderly & information factor \\
\hline
\end{tabular}

\subsection{Main Customers-Based on Cluster Analysis}

According to the common factors obtained in Table 5, the regression algorithm is used to calculate the scores of each factor, and cluster analysis is carried out with it as the variable. The elderly users are classified as a whole. This paper chooses K-means clustering (i.e., rapid clustering method). The idea of this clustering method is to roughly divide the sample into $\mathrm{K}$ initial classes, modify them, and assign samples one by one to their nearest mean class. This paper tries to divide the users into three categories and the results are shown in Table 6 .

Table 6. The distance of clustering.

\begin{tabular}{llll}
\hline clustering & $\mathbf{1}$ & $\mathbf{2}$ & $\mathbf{3}$ \\
\hline 1 & & 6.480 & 5.307 \\
2 & 6.480 & & 9.472 \\
3 & 5.307 & 9.472 & \\
\hline
\end{tabular}

According to the prime criterion determined by the number of classifications, that is, the distance between the various centers must be large, we can see that dividing the whole into three categories meets this condition. Then the final cluster center is got and shown in Table 7 .
Table 7. Clustering.

\begin{tabular}{llll}
\hline & clustering & & \\
\cline { 2 - 4 } & $\mathbf{1}$ & $\mathbf{2}$ & $\mathbf{3}$ \\
\hline technical factor & 7 & 4 & 7 \\
price factor & 7 & 5 & 6 \\
theoretical factor & 12 & 3 & 8 \\
information factor & 4 & 4 & 15 \\
\hline
\end{tabular}

From Table 7, it can be seen that the features are relatively obvious in the three categories that are divided. In the first group of people, the central value of theoretical factors is relatively large. Thus, it gets a conculsion that such elderly people have a greater influence from their professional knowledge and understanding level and they can be called the "theoretical user". In the second group of people, the central values corresponding to the four factors are small and not prominent and they can be called the "blind user". In the third group of people, the central value of the information factor is large, indicating that such elderly people in the choice of old-age care mode pay attention to the attitude of children and the evaluation of other old people's, and they can be called the "objective user". Figure 6 shows a frequency distribution of 348 elderly users in three major types. 
From Figure 6, it can be seen that among the elderly people in the $\mathrm{O} 2 \mathrm{O}$ intelligent pension model, the number of theoretical and objective people is more prominent, accounting for $30.45 \%$ and $56.32 \%$ of samples surveyed, respectively, while the "blind user" only accounts for $13.21 \%$. It can be concluded that the main customers of Tianjin $\mathrm{O} 2 \mathrm{O}$ intelligent pension model are the "objective" users.

\subsection{Characteristics of Main Customers-Based on Living Conditions}

This questionnaire has the option of "Who are you living with?". The answers "live with their children" and "live with spouse and children" can be merged into "live with their children", and the answers "live with spouse", "live alone" and "others" can be merged into "do not live with their children".
Then these two types of elderly can be analyzed.

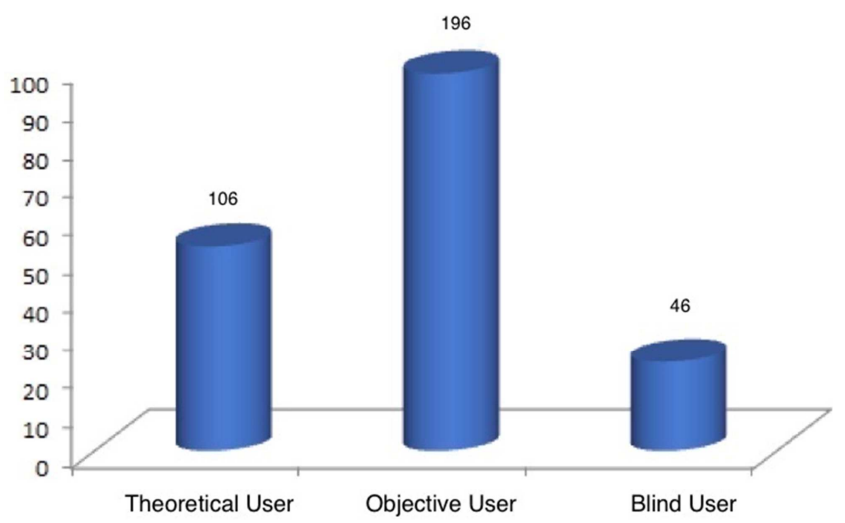

Figure 6. The distribution of users.

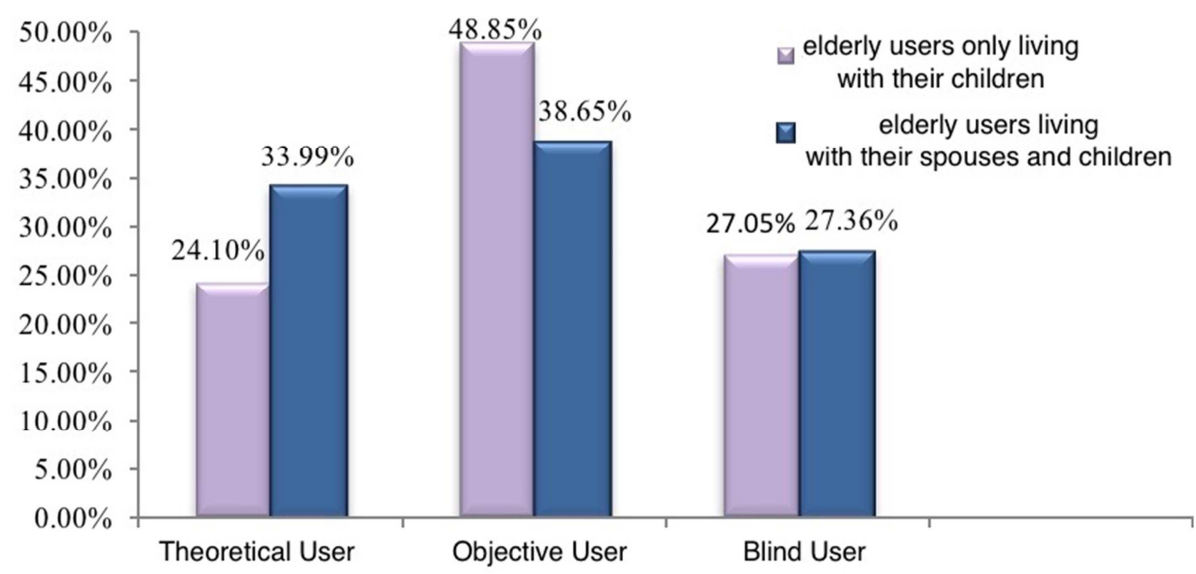

Figure 7. The elderly living with their children.

From Figure 7, it is known that the elderly people who are living with their children are more "objective". Among them, the objective group of the elderly who lived only with the children accounted for $48.85 \%$, and the objective proportion of the elderly who lived with the children and spouses accounted for $38.65 \%$.

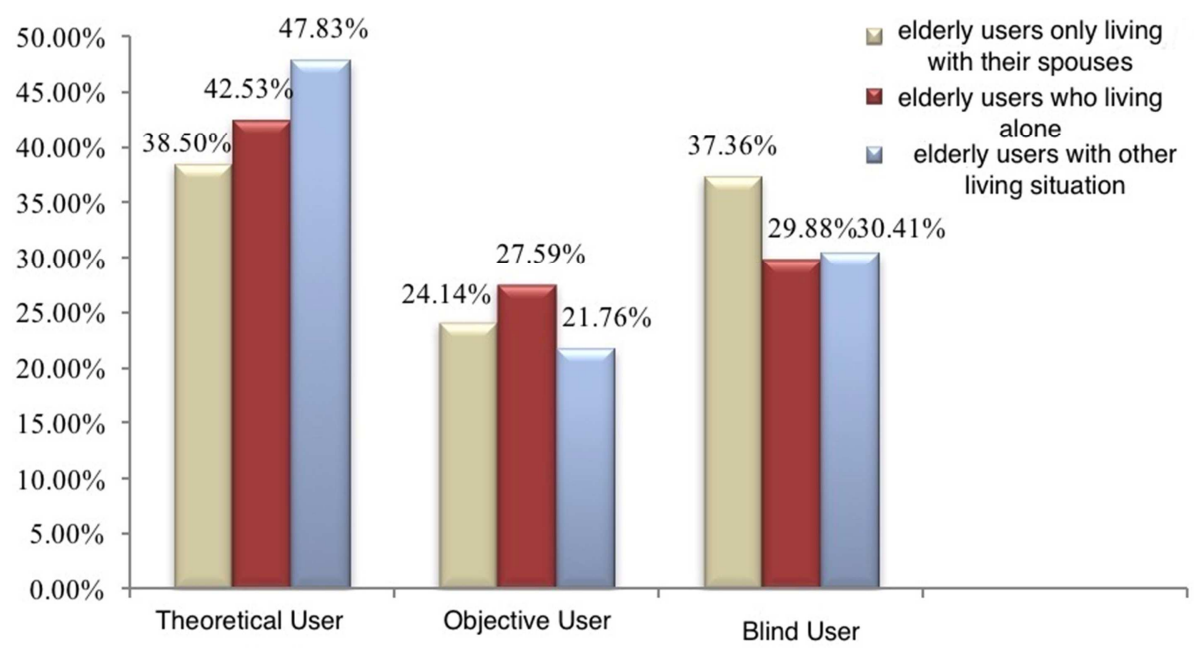

Figure 8. The elderly do not live with their children.

From Figure 8, it can be known that the number of "theoretical" elderly people is high among the elderly people who do not live with their children. There are more "theoretical" elderly who live with their spouses, accounting for $38.50 \%$ of the total, and"objective" elderly are less, accounting for $24.14 \%$. For the elderly living alone, "theoretical" elderly are more, accounting for $42.53 \%$ of the elderly, and "objective" elderly are less, accounting for 
$27.59 \%$. In general, for the main customers who do not live with their children, the number of "objective" elderly is relatively small.

By the above comparative analysis, it is believed that the elderly will pay more attention to their children's attitude towards old-age care when they live with their children. It is easy to follow the advice of their children and also pay attention to the evaluation of other elderly people. On the contrary, for the elderly do not live with their children, it is not easy to listen to the opinions of their children and the evaluation of other elderly. They will make judgements according to their own understanding and their previous professional knowledge.

\subsection{Characteristics of Main Customers-Based on Age}

This paper uses the analysis of one-factor variance to determine whether there are differences in the four common factor scores for different age groups and the results are shown in Table 8.

Table 8. Test for different age groups.

\begin{tabular}{llllll}
\hline & & sum of square & Df & mean square & F \\
\hline & technical factor & 9.471 & 4 & 2.42 & 0.582 \\
comparison & information factor & 156.724 & 4 & 34.573 & 0.530 \\
& theoretical factor & 68.619 & 4 & 14.283 & 3.005 \\
& price factor & 7.423 & 4 & 1.871 & 2.159 \\
& technical factor & 1032.53 & 236 & 3.962 & 0.427 \\
deviation & information factor & 3239.628 & 236 & 12.529 & 0.095 \\
& theoretical factor & 1762.428 & 236 & 7.481 & 0.942 \\
& price factor & 328.548 & 236 & 0.935 \\
\hline
\end{tabular}

From Table 8, it can be seen that when the significance level is $5 \%$, and only the $\mathrm{P}$ value of the information factor is less than the significance level. The results show that the information factor score has significant difference among the elderly in different age groups, while other common factors have no obvious difference among different age groups. In order to describe the difference in information factor scores among users of different age groups more clearly, a line chart of age and information factor scores is drawn, as shown in Figure 9.

It can be seen from Figure 9 that the average level of information factor for the elderly in the $\mathrm{O} 2 \mathrm{O}$ smart pension model between the ages of 60 and 70 is above the 0 scale; for the elderly older than 80 , the average level of the information factor is below the 0 scale, and the overall trend of the score decreases with age. It shows that for the elderly who are relatively younger, it is easier to believe the information obtained, and the number of "objective" elderly is more. With the increase of age, the attention of the elderly to the external information is gradually weakened, and the number of "objective" elderly is gradually decreasing.

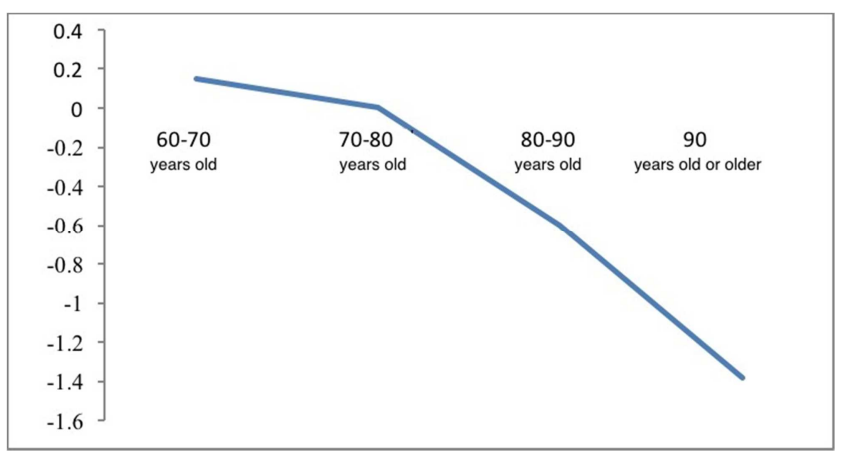

Figure 9. Age and information factor score.

\subsection{Summary}

(1) First of all, according to the scores, it is found that among the seven listed factors, the service quality of the aged care has a greater impact on the choice of old-age care.

(2) Then by the factor analysis, four factors are extracted, i.e., technical factors, information factors, theoretical factors, and price factors.

(3) By the cluster analysis, the elderly users can be divided into three categories, namely, "theoretical", "objective" and "blind". Among them, the number of "objective" elderly is the largest, and thus the "objective" elderly are the main customers of the $\mathrm{O} 2 \mathrm{O}$ intelligent pension model.

(4) Next, the characteristics of the main customers based on different living conditions are analyzed. By comparing the elderly living in "with children" with "not living with children", it is found that most "objective" elderly live with their children.

(5) Finally, the characteristics of the main customers based on different age groups are analyzed. By the univariate test, it is found that for the elderly of different age groups, there will be significant differences in the selection of information factors, and with the increase of age, the scores of information factors tend to decrease.

\section{Prospect Analysis of O2O Smart Pension}

\subsection{Overview of the Prospect}

In the future, with the gradual increase in the number of only children, the disadvantages of traditional home-based care for the elderly will become more serious. Moreover, the traditional Chinese solidified thinking that the children must support their parents will still make the elderly very resistant to the nursing home. Therefore, the status of traditional home-based care and nursing homes will gradually decline. With the development of technology, middle-aged and elderly can accept new technology more easily. In addition, 
government policies support the smart pension model. Therefore, it is believed that the only smart pension model is the mainstream trend of future pension.

However, it is still unclear whether the online intelligent pension model that now accounts for more than $90 \%$ of the smart pension market will continue to dominate the smart pension market, or $\mathrm{O} 2 \mathrm{O}$ smart pension model pioneered by the company will be more competitive. To solve this problem, the elderly of non-O2O smart pension models are investigated.

This survey introduces the complete $\mathrm{O} 2 \mathrm{O}$ smart pension model for the elderly who are not $\mathrm{O} 2 \mathrm{O}$ smart pension users and inquire about which $\mathrm{O} 2 \mathrm{O}$ smart pension service that the elderly would like to enjoy, so that the potential users' needs for the service can be found out.

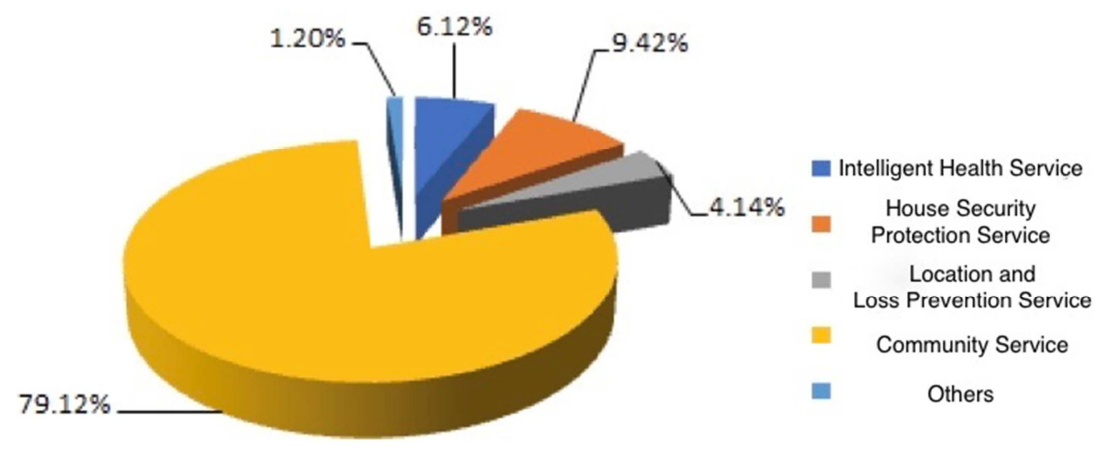

Figure 10. Services that non-users elderly wish to enjoy.

From Figure 10, it can be seen $79.12 \%$ of the elderly choose community business services, $9.42 \%$ for home security services, $6.12 \%$ for health smart watch services, and $4.14 \%$ and $1.20 \%$ for positioning anti-lost service and other services respectively.

According to the data results, most non-users elderly wish to enjoy the community business service in the $\mathrm{O} 2 \mathrm{O}$ smart pension model, which is the service that really attracts the elderly. Off-line community servcie is a major feature of the $\mathrm{O} 2 \mathrm{O}$ smart retirement model, and cannot be provided by the online smart pension system. At the same time, the survey results of the service satisfaction of $\mathrm{O} 2 \mathrm{O}$ smart pension model show that the satisfaction of community business service is higher than other services' satisfaction. And for the moment, the prices of online pension and the $\mathrm{O} 2 \mathrm{O}$ smart pension are basically the same. In summary, the $\mathrm{O} 2 \mathrm{O}$ smart pension model is the real trend of future pension, having a bright future.

\subsection{Logit Model and Analysis}

This paper studies the impact factors for the user's elderly on the prospects of the $\mathrm{O} 2 \mathrm{O}$ smart pension model. Furthermore, this paper proposes some advice to retain the current users and make this model develop better and more competitive in the future. First, the Logit model is constructed.

The Logit model is actually a generalization of the ordinary multiple linear regression model. Using the linear discriminant model to calculate the $\mathrm{Z}$ value is only an abstract concept, which can only be used to judge and cannot explaine from the intuition. The Logit model can solve this problem, specifically, it can overcome the shortcomings of the traditional Mantel-Haenszel analysis method and linear regression analysis, analyze multiple factors including discrete random variables and continuous random variables at one time, and furthermore analyze the mixed effects and interactions of external variables. Logit model analysis is closer to the rich information of the objective situation, and thus a more reasonable explanation of the result can be given. On the other hand, the correlation between the data is fully considered, the goodness of fit of each model is tested and compared, and finally it can be found the Logit model is best fitted. Therefore, the Logit model is used to analyze the data.

Using the software Stata12.0, this paper deletes the elderly who choose the answer of "general" in the question "How do you think the $\mathrm{O} 2 \mathrm{O}$ smart pension model is developing?", and defines good development prospect as $\mathrm{y}=1$, and otherwise $\mathrm{y}=0$. Then this papers uses multiple Logit Regression model, with the evaluation index of old-age research (old-age price (X1), pension quality (X2), pension environment (X3), pension convenience (X4) and pension comfort (X5)) as independent variables, constructs the model of the pension prospect. Finally, this paper has the conclusions shown in Table 9.

Table 9. Results of Logit model.

\begin{tabular}{|c|c|c|c|c|c|c|}
\hline \multirow{2}{*}{\multicolumn{4}{|c|}{ Logistic regression }} & \multicolumn{3}{|c|}{ Number of obs $=531$} \\
\hline & & & & \multicolumn{3}{|c|}{$L R \operatorname{chi} 2(8)=479.58$} \\
\hline \multirow{2}{*}{\multicolumn{4}{|c|}{ Log Likelihood=-8.7005759 }} & \multicolumn{3}{|c|}{ Prob $>$ chi $2=0.0000$} \\
\hline & & & & \multicolumn{3}{|c|}{ Pseudo R2=0.9824 } \\
\hline Pre & Coef. & Std.Err. & $\mathbf{Z}$ & $\mathbf{P}>|\mathbf{z}|$ & {$[95 \%$ Conf } & \\
\hline $\mathrm{X} 1$ & 5.326879 & 4.465323 & 0.87 & 0.002 & -8.232475 & 15.33209 \\
\hline $\mathrm{X} 2$ & 2.327354 & 1.084232 & 3.28 & 0.001 & 1.193124 & 4.422145 \\
\hline $\mathrm{X} 3$ & 3.934248 & 6.004352 & 1.23 & 0.004 & -3.241732 & 23.93211 \\
\hline $\mathrm{X} 4$ & 6.528239 & 1.976532 & 2.98 & 0.012 & 2.632677 & 12.13249 \\
\hline $\mathrm{X} 5$ & 8.489245 & 4.22213 & 1.92 & 0.001 & -2.356429 & 15.78245 \\
\hline -cons & -89.45256 & 64.23112 & -2.28 & 0.02 & -147.3681 & -13.74325 \\
\hline
\end{tabular}


From Table 9, Prob $>$ chi $2=0.0000$, indicating that the model is statistically significant, and $\mathrm{P}$ values of the pension price, pension quality, pension environment, pension convenience, and pension comfort are less than 0.05 , indicating the null hypothesis rejected. Thus, these factors have an impact on the prospects of the $\mathrm{O} 2 \mathrm{O}$ smart pension model and the final expression is

$$
G=\frac{\exp (-89.45+5.33 * X 1+2.33 * X 2+3.93 * X 3+6.53 * X 4+8.49 * X 5)}{1+\exp (-89.45+5.33 * X 1+2.33 * X 2+3.93 * X 3+6.53 * X 4+8.49 * X 5)}
$$

It also be known from Table 9 that the coefficient of pension comfort is the largest, followed by pension convenience and pension price, which means pension comfort has the greatest impact on the forecast of $\mathrm{O} 2 \mathrm{O}$ smart pension model. Therefore, it is the primary task to increase the comfort level of the elderly and the company should regularly improve the elderly's pension comfort through feedback from the elderly. At the same time, the company should also pay attention to the elderly's convenience and old-age prices, providing reasonable pricing and more diversified services to make the elderly's life more convenient.

\section{Conclusion and Suggestion}

\subsection{Conclusion}

In terms of market status, $43.92 \%$ of the elderly have heard of the $\mathrm{O} 2 \mathrm{O}$ smart pension model, which shows it has certain recognition but not high. The $\mathrm{O} 2 \mathrm{O}$ smart pension model has insufficient advertising and does not make good use of propaganda methods such as TV and newspaper. Compared with other ways of pension, the $\mathrm{O} 2 \mathrm{O}$ smart pension users have higher satifaction with the pension, however, lower satisfaction with the pension price.

In terms of the user's current situation, most of the $\mathrm{O} 2 \mathrm{O}$ smart pension users are aged 60-80 years old, biased towards a younger age. The number of elderly choose the $\mathrm{O} 2 \mathrm{O}$ smart pension model does not increase with the increase of the family's annual income, which means whether to choose the $\mathrm{O} 2 \mathrm{O}$ smart pension has nothing to do with the annual income of the elderly family. $\mathrm{O} 2 \mathrm{O}$ smart pension users are less satisfied with the "font size" and "operational difficulty level". They can be divided into "theoretical", "blind" and "objective", and among them the "objective" elderly are the main customers.

In terms of prospects, with the gradual improvement of people's ability to accept technology and the strong support of government policies for the smart pension, the $\mathrm{O} 2 \mathrm{O}$ smart pension model is the real trend of pension in the future. The comfort level have the greatest impact on the forecast of the $\mathrm{O} 2 \mathrm{O}$ smart pension, followed by pension convenience and pension prices.

\subsection{Suggestion}

\subsubsection{Develop Potential Users}

The company should increase the publicity on the radio, appropriately reduce the layout of bulletin boards and the publicity of small advertisements for the elderly. More users know the $\mathrm{O} 2 \mathrm{O}$ smart pension by "broadcast", while more non-users know about it "when passing by." The introduction on the advertisements and bulletin boards are often very general, and there is no price or detailed services information, which affects the choice of the elderly and is the reason why the elderly see the advertisements when passing by and ultimately have no choice. In addition, the main channel for the elderly to obtain information is to listen to the radio, and the cost of broadcasting advertisements is relatively small, and thus the publicity on the radio can make the service system understood more comprehensively.

For the company, the young people who live within 5 kilometers of the community's business location and whose parents are 60-70 years old and live with their parents, should be targeted. The main customers of Tianjin $\mathrm{O} 2 \mathrm{O}$ intelligent pension are the "objective" elderly and the number of "objective" elderly aged 60-70 years old is more. Moreover, when the elderly and their children live together, they will pay more attention to their children's attitude towards old-age care.

\subsubsection{Retain Exisiting Users}

First, the company should reduce the pricing of the $\mathrm{O} 2 \mathrm{O}$ smart pension or adopt a marketing strategy appropriately, making the user's satisfaction with the price closer to the ideal point. According to the comprehensive analysis of descriptive analysis and entropy weight ideal point method, compared with other old-age methods, $\mathrm{O} 2 \mathrm{O}$ intelligent pension users have lower satisfaction with the old-age price.

Second, the company should increase the font size and simplify the operation steps. It is also recommended to set the third side button to directly call the child.

Finally, the company should increase the comfort and convenience of the elderly. The coefficient of pension comfort is the largest, so its change has the greatest impact on the forecast of $\mathrm{O} 2 \mathrm{O}$ smart pension. Therefore, increasing the comfort level of the elderly is the primary task to improve the competitiveness of the $\mathrm{O} 2 \mathrm{O}$ intelligent pension model. The company also should improve the elderly's pension comfort through regular feedback from the elderly.

\section{References}

[1] Q. F. Huang. Research on the development of China's pension service industry. Wuhan University Press, 2014, 202-208.

[2] S. N. Li. "Internet +" and intelligent retirement--based on the investigation of Xiyangli in Nankai district, Economic Research Guide, 2016, 42-63.

[3] H. Zhou. Study on the Life Satisfaction of Urban Elderly under the Community Home Care. Master's thesis, North University, 2017, 2-27.

[4] Y. N. Xu and Y. Zhao. Exploring the Mode of Intelligent Old-age Care in China. Modern Communication, 2017, $16(2): 41-53$. 
[5] M. Qiu. Research on the Development Status and Countermeasures of Intelligent Old-age Industry in Yangzhou City. 2017, 42(3):31-39.

[6] L. J. Sun and X. J. Xing. Improvement of Entropy Weighting Method. Statistics \& Decision Making, 2010, 43(2):31-35.

[7] J. Peng and C. Tian. Comprehensive Evaluation of Regional Economy in Hubei Province Based on Factor Analysis and Cluster Analysis. Shopping Modernization, 2012, 29(5):32-38.

[8] M. Y. Xiao. Decision Model Based on Entropy and Entropy Weight Principle. Knowledge Economy, 53(3):41-43.

[9] D. X. Huang. Multi-factor weight distribution method based on objective information entropy. Systems Engineering Theory and Practice, 2003, 43(5):21-26.
[10] W. Z. Yang. Detailed analysis of SPSS statistical analysis and industry application cases. Beijing: Tsinghua University Press, 2015, 37-42.

[11] Q. G. Ma. Management Statistics: Data Acquisition, Statistical Principles, SPSS Tools and Applied Research. Beijing: Science Press, 2002, 1-52.

[12] J. Q. Zhu. Applied multivariate statistical analysis. Beijing: Science Press, 2012, 10-27.

[13] W. G. Wang. Forecasting and Decision Making. Beijing: China Financial and Economic Publishing House, 2006, 46-58.

[14] Y. Zhu. Smart Pension Blue Book China Smart Care Industry Development Report. Economics News, 2015, 23(3): 41-43. 